\title{
Overuse of Diagnostic Brain Imaging Among Patients With Stage IA Non-Small Cell Lung Cancer
}

Michael G. Milligan, MD, MBA ${ }^{1}$; Angel M. Cronin, $\mathrm{MS}^{2}$; Yolonda Colson, MD, $\mathrm{PhD}^{3}$; Kenneth Kehl, MD, $\mathrm{MPH}^{2}$; Debra N. Yeboa, MD; Deborah Schrag, MD, MPH²; and Aileen B. Chen, MD, MPP4

\begin{abstract}
Background: Among patients diagnosed with stage IA non-small cell lung cancer (NSCLC), the incidence of occult brain metastasis is low, and several professional societies recommend against brain imaging for staging purposes. The goal of this study was to characterize the use of brain imaging among Medicare patients diagnosed with stage IA NSCLC. Methods: Using data from linked SEER-Medicare claims, we identified patients diagnosed with AJCC 8th edition stage IA NSCLC in 2004 through 2013. Patients were classified as having received brain imaging if they underwent head CT or brain MRI from 1 month before to 3 months after diagnosis. We identified factors associated with receipt of brain imaging using multivariable logistic regression. Results: Among 13,809 patients with stage IA NSCLC, $3,417(25 \%)$ underwent brain imaging at time of diagnosis. The rate of brain imaging increased over time, from $23.5 \%$ in 2004 to $28.7 \%$ in $2013(P=.0006)$. There was significant variation in the use of brain imaging across hospital service areas, with rates ranging from $0 \%$ to $64.0 \%$. Factors associated with a greater likelihood of brain imaging included older age (odds ratios [ORs] of 1.16 for $70-74$ years, 1.13 for $75-79$ years, 1.31 for $80-84$ years, and 1.46 for $\geq 85$ years compared with 65-69 years; all $P<.05)$, female sex (OR, 1.09; $P<.05)$, black race (OR 1.23; $P<.05$ ), larger tumor size (ORs of 1.23 for $11-20 \mathrm{~mm}$ and 1.28 for $21-30 \mathrm{~mm}$ tumors vs $1-10 \mathrm{~mm}$ tumors; all $P<.05$ ), and higher modified Charlson-Deyo comorbidity score (OR, 1.28 for score $>1$ vs score of $0 ; P<.05)$. Conclusions: Roughly 1 in 4 patients with stage IA NSCLC received brain imaging at the time of diagnosis despite national recommendations against the practice. Although several patient factors are associated with receipt of brain imaging, there is significant geographic variation across the United States. Closer adherence to clinical guidelines is likely to result in more costeffective care.
\end{abstract}

J Natl Compr Canc Netw 2020;18(5):547-554 doi: $10.6004 /$ jnccn.2019.7384

${ }^{1}$ Harvard Medical School, ${ }^{2}$ Dana-Farber Cancer Institute, and ${ }^{3}$ Massachusetts General Hospital, Boston, Massachusetts; and ${ }^{4}$ The University of Texas MD Anderson Cancer Center, Houston, Texas.

\section{Background}

The brain is a common site of metastasis for non-small cell lung cancer (NSCLC), and many patients undergo brain imaging with MRI or CT before definitive treatment. The hope is that early detection of brain metastases can expedite intracranial treatment while sparing patients from the morbidity of a noncurative pulmonary resection.

However, the utility of brain imaging in asymptomatic patients with early-stage disease seems to be limited. A pooled analysis of retrospective studies revealed that just $3 \%$ of all patients with NSCLC and a negative neurologic examination presented with brain metastases. ${ }^{1}$ Another study, limited to patients with stage I NSCLC, found that brain metastases were prevalent just $1.3 \%$ of the time and were unlikely to be clinically silent, leading to neurologic symptoms in $60 \%$ of cases. ${ }^{2}$ Thus, the routine use of brain imaging to screen for clinically occult brain metastases in these patients is unnecessary and can lead to potentially harmful delays in treatment. ${ }^{2,3}$

Consequently, multiple specialty societies have issued recommendations against brain imaging for staging purposes in asymptomatic patients with early-stage NSCLC. Since 2004, NCCN has recommended brain imaging be performed as part of the routine pretreatment evaluation only among patients with clinical stage II or higher NSCLC. ${ }^{4}$ In 2010, NCCN broadened its recommendation to include the optional use of brain imaging for patients with stage IB disease. ${ }^{5,6}$ Meanwhile, since 2003, the American College of Chest Physicians has recommended pretreatment brain imaging only for patients with clinical stage III or IV NSCLC. ${ }^{7}$ Going further, in 2013, the Society of Thoracic Surgeons, in conjunction with the ABIM Foundation, published a series of Choosing Wisely guidelines to discourage specific low-value medical interventions. One of their recommendations explicitly stated that "patients with suspected or biopsy-proven stage I NSCLC do not require brain imaging before definitive care in the absence of neurologic symptoms." ${ }^{\prime}$

Although specific recommendations differ somewhat, there is unanimity against the use of brain imaging 
to screen for brain metastases among asymptomatic patients with stage IA NSCLC. A recent study of participants diagnosed with stage IA NSCLC during the National Lung Screening Trial (NLST) found that more than 1 in 10 underwent brain imaging for staging purposes, with significant variation in clinical practice across study sites. ${ }^{9}$ Goals of our study were to describe the use of brain imaging at a population-based level among Medicare patients with stage IA NSCLC and to identify the demographic and clinical factors associated with receipt of brain imaging.

\section{Methods}

\section{Data Sources}

This retrospective cohort study used the SEER-Medicare dataset to characterize the clinical workup, treatment, and outcomes of patients with stage IA NSCLC in the United States. The SEER program is a population-based cancer database comprising 17 regional and statewide cancer registries covering approximately $28 \%$ of the US population. ${ }^{10}$ In a collaboration between the NCI, which administers the SEER program, and the Centers for Medicare \& Medicaid Services, this registry information has been linked to individual claims data for all adults enrolled in fee-for-service Medicare. ${ }^{11}$ The present study was deemed exempt from Institutional Review Board review.

\section{Study Sample}

Patients diagnosed with AJCC 8th edition stage IA NSCLC in 2004 through 2013 were identified from the SEER database. ${ }^{12}$ Patients were excluded if they were aged $<65$ years, lacked a pathologic confirmation of NSCLC, had a previous cancer, or did not have continuous Medicare Parts A and B coverage in the period between 12 months before cancer diagnosis and 12 months after diagnosis or death, whichever came first. Demographic information, including the hospital service area (HSA $)^{13}$ in which each patient received cancer care, was also extracted.

\section{Clinical Course and Brain Imaging}

We used the Patient Entitlement and Diagnosis Summary File to determine whether site-specific surgery was performed (a dichotomous variable) and to calculate the length of survival after cancer diagnosis. ICD-9 and CPT codes were used to identify interventions recorded in the Medicare Provider Analysis and Review file and Outpatient Standard Analytical File of the Medicare claims data. ${ }^{14}$ Our primary outcome was the use of brain imaging at time of diagnosis, defined broadly as the receipt of any head CT (CPT codes 70450 and 70460) or brain MRI (CPT codes 70551 and 70553) at any time from 1 month before until 3 months after cancer diagnosis. Modified
Charlson-Deyo comorbidity scores were ascertained for the 12 months before diagnosis using Deyo's implementation of the Charlson score applied to both inpatient and outpatient claims, ${ }^{15,16}$ as suggested by Klabunde et al $^{17}$ for patients with cancer.

\section{Statistical Analysis}

All statistical methods were performed using SAS 9.4 (SAS Institute Inc.). We assessed the baseline characteristics of patients included in our sample, grouped by receipt of brain imaging. Categorical variables were reported as counts and percentages, and groups were compared using chi-square tests for significance. Continuous

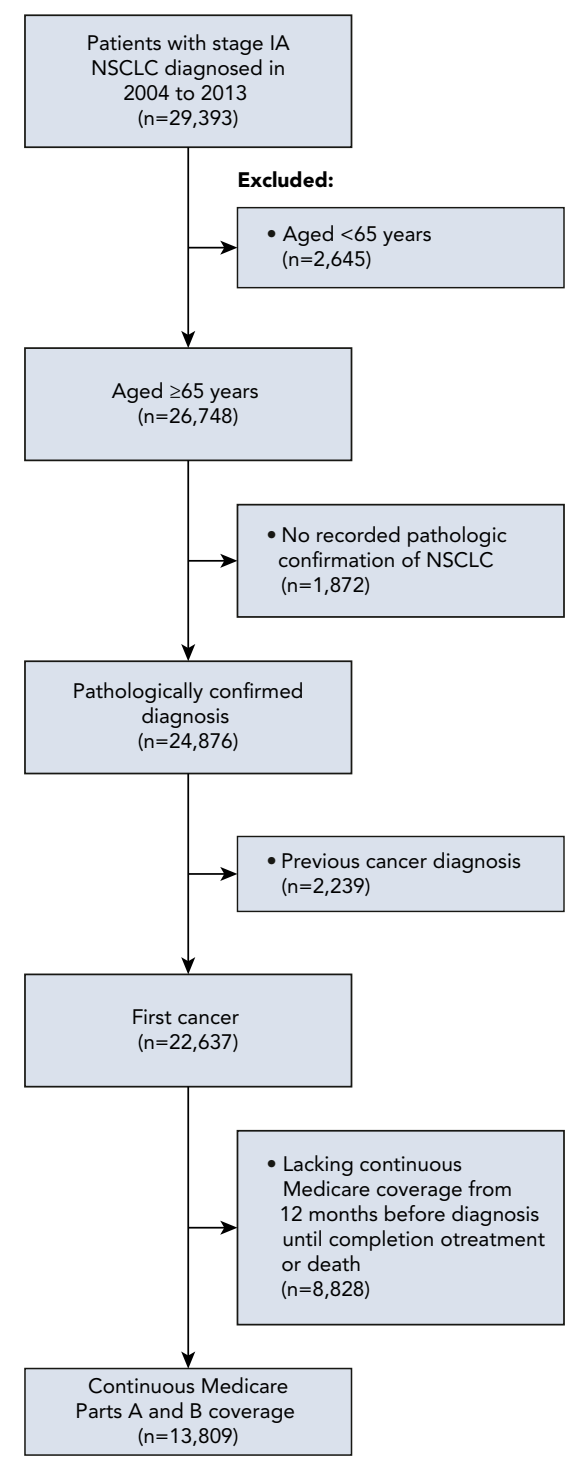

Figure 1. Study cohort.

Abbreviation: NSCLC, non-small cell lung cancer. 


\section{Table 1. Baseline Demographic and Clinical Characteristics}

\begin{tabular}{|c|c|c|c|c|}
\hline Variable & $\begin{array}{l}\text { Overall Cohort } \\
\text { n (\%) }\end{array}$ & $\begin{array}{c}\text { Received Brain Imaging } \\
\mathbf{n}(\%)\end{array}$ & $\begin{array}{c}\text { No Brain Imaging } \\
n(\%)\end{array}$ & P Value ${ }^{a}$ \\
\hline Total, $\mathrm{n}$ & $13,809(100)$ & $3,417(25)$ & $10,392(75)$ & \\
\hline Male & $6,014(44)$ & $1,425(24)$ & $4,589(76)$ & \\
\hline Female & $7,795(56)$ & $1,992(26)$ & $5,803(74)$ & \\
\hline $70-74$ & $3,738(27)$ & $916(25)$ & $2,822(75)$ & \\
\hline $75-79$ & $3,387(25)$ & $827(24)$ & $2,560(76)$ & \\
\hline $80-84$ & $2,246(16)$ & $624(28)$ & $1,622(72)$ & \\
\hline$\geq 85$ & $975(7)$ & $300(31)$ & 675 (69) & \\
\hline Other & $750(5)$ & $181(24)$ & $569(76)$ & \\
\hline Geographic setting & & & & .1247 \\
\hline Urban & $12,315(89)$ & $3,072(25)$ & $9,243(75)$ & \\
\hline Rural & $1,494(11)$ & $345(23)$ & $1,149(77)$ & \\
\hline Relationship status & & & & $<.0001$ \\
\hline Married & $7,181(52)$ & $1,674(23)$ & $5,507(77)$ & \\
\hline Unmarried & $6,628(48)$ & $1,743(26)$ & $4,885(74)$ & \\
\hline US census region & & & & $<.0001$ \\
\hline Northeast & $3,111(23)$ & $836(27)$ & $2,275(73)$ & \\
\hline Lower lobe & $4,334(31)$ & $1,047(24)$ & $3,287(76)$ & \\
\hline Other & $268(2)$ & $69(26)$ & $199(74)$ & \\
\hline Laterality & & & & .3809 \\
\hline Right & $7,933(57)$ & $1,935(24)$ & $5,998(76)$ & \\
\hline Left & $5,876(43)$ & $1,482(25)$ & $4,394(75)$ & \\
\hline Cancer histology & & & & .0037 \\
\hline Squamous & $4,014(29)$ & $1,009(25)$ & $3,005(75)$ & \\
\hline Nonsquamous & $10,207(74)$ & $2,820(28)$ & $7,387(72)$ & \\
\hline Grade & & & & $<.0001$ \\
\hline Low-intermediate & $7,257(53)$ & $1,680(23)$ & $5,577(77)$ & \\
\hline High & $3,732(27)$ & $922(25)$ & $2,810(75)$ & \\
\hline Unknown & $2,820(20)$ & $815(29)$ & $2,005(71)$ & \\
\hline Pathologic T stage & & & & $<.0001$ \\
\hline $\mathrm{IA}$ & $7,802(56)$ & $1,768(23)$ & $6,034(77)$ & \\
\hline IB & $5,887(43)$ & $1,613(27)$ & $4,274(73)$ & \\
\hline
\end{tabular}




\begin{tabular}{|c|c|c|c|c|}
\hline Variable & $\begin{array}{l}\text { Overall Cohort } \\
\text { n (\%) }\end{array}$ & $\begin{array}{c}\text { Received Brain Imaging } \\
\text { n (\%) }\end{array}$ & $\begin{array}{c}\text { No Brain Imaging } \\
n(\%)\end{array}$ & $P$ Value ${ }^{a}$ \\
\hline \multicolumn{4}{|c|}{ Charlson-Deyo comorbidity score } & $<.0001$ \\
\hline 0 & 5,117 (37) & $1,152(23)$ & 3,965 (77) & \\
\hline 1 & $4,258(31)$ & $1,022(24)$ & $3,236(76)$ & \\
\hline 2 & $4,434(32)$ & $1,243(28)$ & $3,191(72)$ & \\
\hline \multicolumn{4}{|c|}{ Receipt of surgery within $6 \mathrm{mo}$ of diagnosis } & .1505 \\
\hline Yes & $7,866(57)$ & $1,967(25)$ & $5,899(75)$ & \\
\hline No & $5,943(43)$ & 1,450 (24) & $4,493(76)$ & \\
\hline
\end{tabular}

aBold indicates statistically significant $P$ values $(P<.05)$.

variables were reported as medians and interquartile ranges and compared via Wilcoxon rank-sum tests.

Univariable logistic regression was used to characterize the associations between demographic and clinical features and the likelihood of receiving brain imaging for staging. We modeled age, sex, race, geographic setting (urban vs rural), US census region, relationship status, cancer histology, pathologic tumor stage, Charlson-Deyo comorbidity score, and receipt of surgery within 6 months as categorical variables. Tumor size was modeled as a continuous variable. We performed a multivariable logistic regression for the likelihood of receiving brain imaging for staging, including age, sex, race, geographic setting, relationship status, tumor size, cancer histology, comorbidity status, and receipt of pulmonary resection as categorical variables. The statistical significance of trends was calculated using the Mann-Kendall test.

\section{Results}

Among 29,393 Medicare patients diagnosed with stage IA NSCLC (T1N0M0) in 2004 through 2013, a total of 13,809 patients met inclusion criteria (Figure 1). Median age of the cohort was 75 years, $56 \%$ were women, and median tumor size was $20 \mathrm{~mm}$; baseline demographic

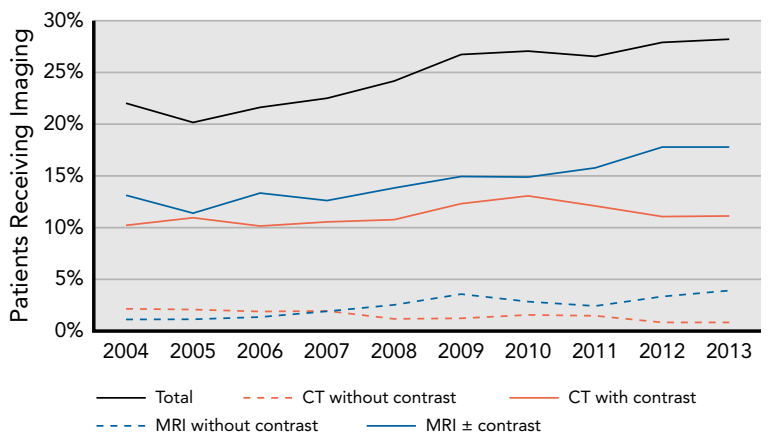

Figure 2. Proportion of patients receiving brain imaging at time of diagnosis. and clinical characteristics of the cohort are summarized in Table 1. Over the study period, the rate of brain imaging at diagnosis increased from $23.5 \%$ in 2004 to $28.7 \%$ in 2013, representing a statistically significant trend $(P=.0006)$ (Figure 2).

Overall, $25 \%$ of patients underwent at least one modality of brain imaging in the period between 1 month before and 3 months after cancer diagnosis: $1.5 \%$ underwent head CT without contrast enhancement (CT-), $11.3 \%$ underwent head CT with contrast enhancement $(\mathrm{CT}+), 2.4 \%$ underwent brain MRI without gadolinium contrast enhancement (MRI-), and $14 \%$ underwent brain MRI with and without gadolinium contrast enhancement (MRI+). Most patients who received brain imaging received only 1 type of brain imaging (85.4\%), whereas $13.7 \%$ received 2 types and $0.9 \%$ received 3 types. Imaging tended to occur soon after cancer diagnosis, with medians of $11.0,12.5,12.0$, and 18.0 days after diagnosis for CT-, CT + , MRI-, and MRI+, respectively.

In univariable analysis, factors associated with greater use of brain imaging included older age (odds ratios [ORs] of 1.17 for $70-74$ years, $P=.0042$; 1.18 for $75-79$ years, $P=.0037$; 1.39 for $80-84$ years, $P<.0001$; and 1.576 for $\geq 85$ years, $P<.0001$; vs $65-69$ years), female sex (OR, 1.10; $P=.145)$, black race (OR, $1.27 ; P=.0014)$, and unmarried relationship status (OR, 1.17; $P<.0001)$. In addition, patients receiving treatment in the South (OR, $0.89 ; P=.0484$ ) or West (OR, $0.85 ; P=.0029$ ) regions of the United States were less likely to receive brain imaging than those in the Northeast region. Clinically, patients with greater comorbidities (OR of 1.31 for modified Charlson-Deyo comorbidity score of $>1$ vs $0, P<.0001$ ) and larger tumors (ORs of 1.26 for $11-20 \mathrm{~mm}$ tumors $[P=.0030], 1.57$ for $21-30 \mathrm{~mm}$ tumors $[P<.0001]$, vs $1-10$ $\mathrm{mm}$ tumors) were more likely to receive brain imaging (Table 2). Receipt of brain imaging was not associated with lung resection within 6 months of diagnosis (OR of 0.96 for no surgery vs surgery; $P=.31$ ). In multivariable 
Table 2. Univariable Analysis of Associations With Brain Imaging

\begin{tabular}{|c|c|c|}
\hline Characteristic & OR $(95 \% \mathrm{Cl})$ & $P$ Value ${ }^{a}$ \\
\hline \multicolumn{3}{|l|}{ Age, $y$} \\
\hline $65-69$ & Ref & \\
\hline $70-74$ & $1.17(1.05-1.30)$ & .0042 \\
\hline $75-79$ & $1.18(1.05-1.32)$ & .0037 \\
\hline 80-84 & $1.39(1.23-1.57)$ & $<.0001$ \\
\hline$\geq 85$ & $1.57(1.34-1.83)$ & $<.0001$ \\
\hline \multicolumn{3}{|l|}{ Sex } \\
\hline Male & Ref & \\
\hline Female & $1.10(1.02-1.19)$ & .0145 \\
\hline \multicolumn{3}{|l|}{ Race } \\
\hline White & Ref & \\
\hline Black & $1.27(1.10-1.47)$ & .0014 \\
\hline Other & $0.94(0.80-1.12)$ & .5142 \\
\hline \multicolumn{3}{|c|}{ Geographic setting } \\
\hline Urban & Ref & \\
\hline Rural & $0.87(0.76-0.99)$ & .0329 \\
\hline \multicolumn{3}{|l|}{ Relationship status } \\
\hline Married & Ref & \\
\hline Unmarried & $1.17(1.08-1.26)$ & $<.0001$ \\
\hline \multicolumn{3}{|l|}{ US census region } \\
\hline Northeast & Ref & \\
\hline Midwest & $0.96(0.91-1.03)$ & .1841 \\
\hline South & $0.89(0.78-0.99)$ & .0484 \\
\hline West & $0.85(0.78-0.93)$ & .0029 \\
\hline \multicolumn{3}{|l|}{ Cancer histology } \\
\hline Squamous & Ref & \\
\hline Nonsquamous & $1.01(0.93-1.11)$ & .7542 \\
\hline \multicolumn{3}{|l|}{ Pathologic T stage } \\
\hline IA & Ref & \\
\hline IB & $1.29(1.19-1.39)$ & $<.0001$ \\
\hline \multicolumn{3}{|c|}{ Tumor size (categorical), mm } \\
\hline $1-10$ & Ref & \\
\hline $11-20$ & $1.26(1.08-1.46)$ & .0030 \\
\hline $21-30$ & $1.57(1.35-1.82)$ & $<.0001$ \\
\hline \multicolumn{3}{|c|}{ Charlson-Deyo comorbidity score } \\
\hline 0 & Ref & \\
\hline 1 & $1.09(0.99-1.20)$ & .0710 \\
\hline 2 & $1.31(1.20-1.44)$ & $<.0001$ \\
\hline \multicolumn{3}{|c|}{ Receipt of surgery within 6 mo of diagnosis } \\
\hline Yes & Ref & \\
\hline No & $0.96(0.89-1.03)$ & .3100 \\
\hline
\end{tabular}

Abbreviation: $O R$, odds ratio.

aBold indicates statistically significant $P$ values $(P<.05)$. analysis, older age, female sex, black race, larger tumor size, and increasing comorbidity score were associated with increased likelihood of receiving brain imaging (Table 3).

There was significant variation in the frequency of brain imaging across different HSAs. Among those that treated $\geq 20$ patients in our cohort during the study period, the median rate of brain imaging was $23.6 \%$, with a minimum of $0 \%$ and a maximum of $64.0 \%$ (Figure $3 \mathrm{~A}$ ). There was no association between the number of patients seen in each HSA and the proportion of patients receiving brain imaging in that HSA. Additionally, the rate of brain imaging did not correlate with the rate of lung-directed surgery that was performed in an HSA (Figure 3B).

\section{Discussion}

In this retrospective cohort study of Medicare patients diagnosed in SEER surveillance areas, we found that more than 1 in 4 patients diagnosed with stage IA NSCLC in 2004 through 2013 received brain imaging at time of diagnosis. Despite the publication and dissemination of guidelines recommending against this practice, the annual rate of brain imaging increased over the study period. In addition, we found a significant variation in practice across different HSAs. To our knowledge, this is the first study to characterize practice patterns of brain imaging among patients with a new diagnosis of stage IA NSCLC in a nationally representative cohort in the United States. However, our results echo previous, non-population-based studies from around the world that reported on the general overuse ${ }^{2,18,19}$ and clinical variation $^{9,20}$ of brain imaging in similar patients.

Medicare claims revealed that most patients who received brain imaging underwent $\mathrm{CT}+$ or $\mathrm{MRI}+$. MRI+ is generally more sensitive, especially for detecting smaller brain metastases. Therefore, NCCN recommends MRI+ over CT + for the evaluation of brain metastases in patients with stage II or higher NSCLC, although it does endorse $\mathrm{CT}+$ in patients when MRI is unavailable. ${ }^{21-23}$ In practice, however, CT + is faster, cheaper, and more readily available than MRI+ while still being able to identify brain metastases in most patients. ${ }^{22,24}$ Furthermore, use of MRI+ for brain metastasis screening in patients with potentially operable NSCLC does not impart a survival advantage over CT + alone, and both modalities are recommended equally by the American College of Chest Physicians for screening in patients with stage III or higher NSCLC. ${ }^{25,26}$

Neither imaging modality is recommended for the detection of brain metastases without contrast enhancement. However, a small fraction of patients in this cohort received CT - or MRI-. MRI- is inferior to MRI+ but may be used in patients in whom there is a concern for gadolinium toxicity. ${ }^{27}$ Likewise, CT - is unable to 


\begin{tabular}{|c|c|c|}
\hline Characteristic & OR $(95 \% \mathrm{Cl})$ & $P$ Value $^{\mathrm{a}}$ \\
\hline \multicolumn{3}{|l|}{ Age, y } \\
\hline $70-74$ & $1.16(1.04-1.30)$ & .0081 \\
\hline $75-79$ & $1.13(1.01-1.26)$ & .0334 \\
\hline $80-84$ & $1.31(1.16-1.48)$ & $<.0001$ \\
\hline$\geq 85$ & $1.46(1.24-1.71)$ & $<.0001$ \\
\hline \multicolumn{3}{|l|}{ Sex } \\
\hline Female & $1.09(1.01-1.19)$ & .0359 \\
\hline \multicolumn{3}{|l|}{ Race } \\
\hline Black & $1.23(1.06-1.43)$ & .0055 \\
\hline Other & $0.93(0.78-1.10)$ & .4091 \\
\hline \multicolumn{3}{|l|}{ Geographic setting } \\
\hline Rural & $0.88(0.77-1.00)$ & .0506 \\
\hline \multicolumn{3}{|l|}{ Relationship status } \\
\hline Unmarried & $1.09(1.00-1.18)$ & .0599 \\
\hline \multicolumn{3}{|l|}{ Cancer histology } \\
\hline Squamous & $0.99(0.90-1.08)$ & .7882 \\
\hline Carcinoma NOS & $1.12(0.98-1.26)$ & .0895 \\
\hline \multicolumn{3}{|l|}{ Tumor size, mm } \\
\hline $11-20$ & $1.23(1.06-1.43)$ & .0083 \\
\hline $21-30$ & $1.51(1.30-1.76)$ & $<.0001$ \\
\hline \multicolumn{3}{|c|}{ Charlson-Deyo comorbidity score } \\
\hline 1 & $1.08(0.98-1.20)$ & .1020 \\
\hline 2 & $1.28(1.17-1.41)$ & $<.0001$ \\
\hline \multicolumn{3}{|c|}{ Receipt of surgery within $6 \mathrm{mo}$ of diagnosis } \\
\hline No & $0.93(0.99-1.17)$ & .0666 \\
\hline
\end{tabular}

Abbreviations: NOS, not otherwise specified; OR, odds ratio. aBold indicates statistically significant $P$ values $(P<.05)$.

identify most potential brain metastases, but it may be used in cases of previously unknown cancer or as a first step to rule out intracranial hemorrhage in patients with new neurologic symptoms. ${ }^{28}$ Notably, 51 (24\%) of the 212 patients in this cohort who received CT- also underwent CT + within the first 3 months of cancer diagnosis. It is possible that some of these patients may have reported neurologic symptoms and initially had workup with $\mathrm{CT}-$, thus representing a reasonable indication for imaging. However, even if all patients who received non-contrast-enhanced imaging with either MRI or CT were removed from this cohort, the overall rate of non-guideline-recommended imaging is still high at $>20 \%$.

Our results are largely in line with those recently reported by Balekian et al..$^{9}$ In their study of patients from the NLST diagnosed with screen-detected stage IA NSCLC at 1 of 33 participating academic medical centers in 2002 through 2004, they found that $12 \%$ of patients underwent brain imaging to assess for potential intracranial metastases. They also reported significant variation in the use of brain imaging across different medical centers, with rates ranging between $0 \%$ and $80 \% .{ }^{9}$ Our study revealed even higher rates of brain imaging, possibly due to the older age of our cohort and the inclusion of patients from a broader set of clinical settings, including academic medical centers, community hospitals, and private clinics.

Notably different between the 2 studies, however, are the clinical and demographic factors associated with brain imaging. Balekian et $\mathrm{al}^{9}$ found that brain imaging was more likely to occur in patients with larger tumors and in those who ultimately underwent pulmonary resection. In our study, however, the rate of brain imaging was not different between patients who did or did not undergo lung-directed surgery. Even when adjusted for factors known to affect the likelihood of receiving surgery (eg, patient age and comorbidity status), no association was found. Previous studies have reasonably suggested that brain imaging is most likely to occur before surgery, because practitioners seek to rule out any extrathoracic disease before exposing their patients to the morbidity associated with surgery. ${ }^{2,9,20}$ Therefore, the lack of association found in this study was surprising and may have been due, in part, to the lowerthan-expected overall rate of surgery observed in our cohort-approximately $63 \%$. A previous review of the SEER-Medicare database reported that roughly $76 \%$ of all patients with resectable NSCLC underwent pulmonary resection in 1985 through $1993,{ }^{29}$ and Balekian et al ${ }^{9}$ reported an $80 \%$ rate in their study. Patients in our study tended to be older and to have greater comorbidities, suggesting that fewer of them may have been considered surgical candidates, potentially leading them to have received alternative treatments such as radiotherapy, which became more widely available across the United States during our study period. ${ }^{30,31}$

Instead, factors associated with the receipt of brain imaging in this study were larger tumor size, older age at diagnosis, a greater burden of comorbidities, and nonwhite race. The relationship between tumor size and likelihood of imaging is linear, suggesting that physicians may have had a greater concern for potential extrathoracic metastases with larger primary tumors. This behavior would be consistent with previous data that showed an increased likelihood of metastases and poorer overall survival among patients with stage IA NSCLC with tumors $>2 \mathrm{~cm} .^{9,32,33}$ The impacts of patient age and comorbidity status are less clear. On the one hand, older patients with NSCLC and those with greater comorbidities are less likely to receive potentially curative, 
A

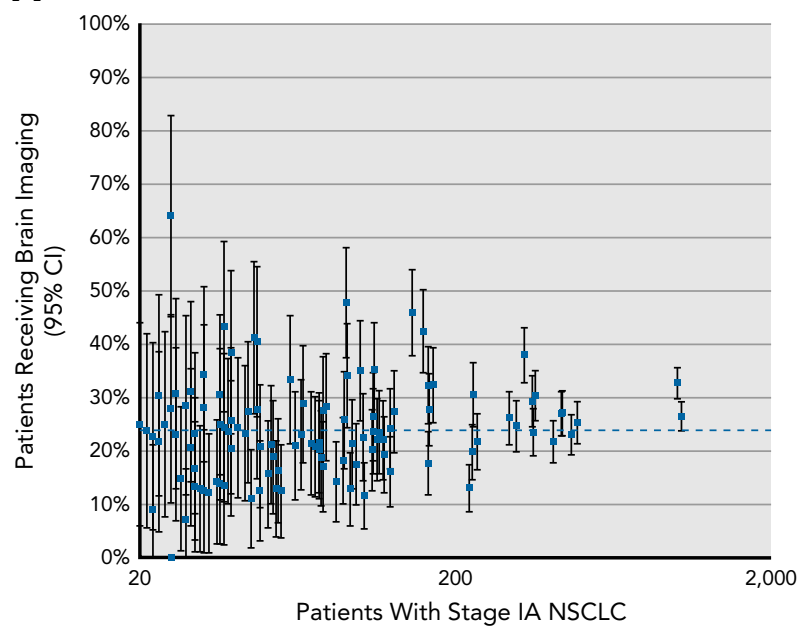

B

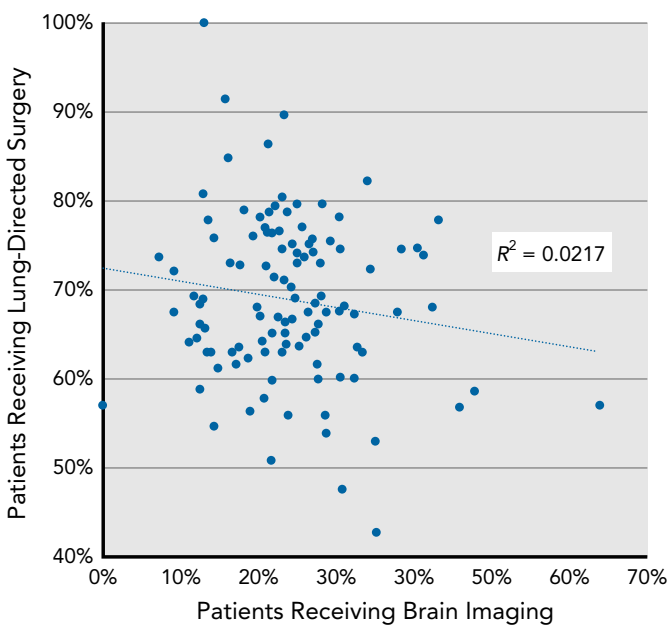

Figure 3. Rates of (A) brain imaging by HSA, and (B) lung-directed surgery versus rates of brain imaging, by HSA. Abbreviations: HSA, hospital service area; NSCLC, non-small cell lung cancer.

guideline-recommended forms of treatment, ${ }^{34,35}$ which may reflect a degree of ageism among clinicians when selecting treatment plans ${ }^{36}$ Another possibility, however, is that older, sicker patients may be more likely to report potentially concerning neurologic symptoms that would warrant brain imaging, a factor that this study was unable to ascertain. Notably, nonwhite Americans were more likely to receive non-recommended routine brain imaging after a diagnosis of stage IA NSCLC. This finding suggests that there may be racial disparities in the receipt of guideline-recommended care, and echoes other studies that have shown disparities in the rates of lung cancer screening, ${ }^{37}$ curative resection of early-stage disease, ${ }^{29}$ and overall survival with NSCLC. ${ }^{38}$

Given that our analysis relied on a national cancer registry and associated claims data, there are some incumbent limitations to consider. Our conclusions only apply to the population analyzed-namely, elderly Americans with a final diagnosis of stage IA NSCLC who had continual Medicare Parts A and B coverage and received care in locations that reported to the SEER registry. We also excluded patients who may have initially presented with $\mathrm{Tl}$ disease but then were diagnosed with an intracranial metastasis, either because of symptomdirected clinical analysis or routine brain imaging. However, prior studies have shown that such patients only represent a small fraction of the total population presenting with T1 NSCLC, ${ }^{2,3,9}$ and including these patients would have likely increased the apparent rate of brain imaging in our study. In addition, we were unable to assess whether patients reported neurologic symptoms or had focal neurologic findings on clinical examination who thus would have warranted brain imaging. It is unlikely, however, that neurologic symptoms alone could have led to the high rate of brain imaging and significant clinical variation we observed.

\section{Conclusions}

This retrospective analysis of the SEER-Medicare cancer registry suggests overuse of unnecessary brain imaging in patients with stage IA NSCLC across the United States, and revealed significant geographic variation in clinical practice. This variation may stem from clinical uncertainty, localized differences in clinical training or the availability of radiologic testing, or a general lack of familiarity with national recommendations. Efforts to disseminate evidence-based best practices, such as those recommended in the Choosing Wisely guidelines, may help improve clinical outcomes while increasing the value of care provided to patients across the United States. Future studies are warranted to assess the impact of such outreach programs, and efforts should be made to improve their effectiveness.

Submitted July 28, 2019; accepted for publication December 4, 2019

Author contributions: Data analysis: Milligan, Cronin, Chen. Project direction: Colson, Kehl, Yeboa, Schrag, Chen. Manuscript preparation: Milligan Review of manuscript: Colson, Kehl, Yeboa, Schrag, Chen. Editing of manuscript: Cronin, Colson, Kehl, Yeboa, Schrag, Chen.

Disclosures: Dr. Schrag has disclosed that she has received consultant fees from Pfizer. The remaining authors have not received any financial consideration from any person or organization to support the preparation, analysis, results, or discussion of this article.

Correspondence: Aileen B. Chen, MD, MPP, The University of Texas MD Anderson Cancer Center, 1515 Holcombe Boulevard, Unit 97, Houston, TX 77030. Email: achen6@mdanderson.org 


\section{References}

1. Toloza EM, Harpole L, McCrory DC. Noninvasive staging of non-small cell lung cancer: a review of the current evidence. Chest 2003;123(1 Suppl): 137S-146S.

2. Tanaka K, Kubota K, Kodama T, et al. Extrathoracic staging is not necessary for non-small-cell lung cancer with clinical stage T1-2 N0. Ann Thorac Surg 1999;68:1039-1042.

3. Colice GL, Birkmeyer JD, Black WC, et al. Cost-effectiveness of head $\mathrm{CT}$ in patients with lung cancer without clinical evidence of metastases. Chest 1995;108:1264-1271.

4. Ettinger DS, Argiris A, Bepler G, et al. NCCN Clinical Practice Guidelines in Oncology: Non-Small Cell Lung Cancer. Version 1.2004. Obtained with permission from NCCN February 2, 2019. To view the most recent version, visit NCCN.org.

5. Ettinger DS, Akerley W, Bepler G, et al. NCCN Clinical Practice Guidelines in Oncology: Non-Small Cell Lung Cancer. Version 1.2010. Obtained with permission from NCCN February 2, 2019. To view the most recent version, visit NCCN.org

6. Ettinger DS, Wood DE, Aggarwal C, et al. NCCN Clinical Practice Guidelines in Oncology: Non-Small Cell Lung Cancer. Version 3.2020. Accessed March 9, 2020. To view the most recent version, visit NCCN.org

7. Silvestri GA, Tanoue LT, Margolis ML, et al. The noninvasive staging of non-small cell lung cancer: the guidelines. Chest 2003;123(1 Suppl): 147S-156S.

8. Wood DE, Mitchell JD, Schmitz DS, et al. Choosing Wisely: cardiothoracic surgeons partnering with patients to make good health care decisions. Ann Thorac Surg 2013;95:1130-1135.

9. Balekian AA, Fisher JM, Gould MK. Brain imaging for staging of patients with clinical stage IA non-small cell lung cancer in the National Lung Screening Trial: adherence with recommendations from the Choose Wisely campaign. Chest 2016;149:943-950.

10. $\mathrm{NCl}$ SEER. Number of persons by race and Hispanic ethnicity for SEER participants (2010 census data). Accessed February 2, 2019. Available at https://seer.cancer.gov/registries/data.html\#a6

11. Warren JL, Klabunde CN, Schrag D, et al. Overview of the SEERMedicare data: content, research applications, and generalizability to the United States elderly population. Med Care 2002;40(8 Suppl):IV3-IV-18

12. Amin MB, Edge $S$, Greene $F$, et al., eds. AJCC Cancer Staging Manual, 8th ed. New York, NY: Springer; 2017. https://doi.org/10.1007/9783-319-40618-3

13. Schrag D, Bach PB, Dahlman C, et al. Identifying and measuring hospital characteristics using the SEER-Medicare data and other claims-based sources. Med Care 2002;40(8 Suppl):IV-96-IV-103.

14. Engels EA, Pfeiffer RM, Ricker W, et al. Use of Surveillance, Epidemiology, and End Results-Medicare data to conduct case-control studies of cancer among the US elderly. Am J Epidemiol 2011;174:860-870.

15. Charlson ME, Pompei $P$, Ales $K L$, et al. A new method of classifying prognostic comorbidity in longitudinal studies: development and validation. J Chronic Dis 1987;40:373-383.

16. Deyo RA, Cherkin DC, Ciol MA. Adapting a clinical comorbidity index for use with ICD-9-CM administrative databases. J Clin Epidemiol 1992;45: 613-619.

17. Klabunde CN, Potosky AL, Legler JM, et al. Development of a comorbidity index using physician claims data. J Clin Epidemiol 2000;53: 1258-1267.

18. Diaz ME, Debowski M, Hukins $C$, et al. Non-small cell lung cancer brain metastasis screening in the era of positron emission tomography-CT staging: current practice and outcomes. J Med Imaging Radiat Oncol 2018;62:383-388
19. Hudson $Z$, Internullo E, Edey A, et al. Brain imaging before primary lung cancer resection: a controversial topic. Ecancermedicalscience 2017; 11:749.

20. Hudson BJ, Crawford MB, Curtin JJ. Brain imaging in lung cancer patients without symptoms of brain metastases: a national survey of current practice in England. Clin Radiol 2015;70:610-613.

21. Schellinger PD, Meinck HM, Thron A. Diagnostic accuracy of MRI compared to CCT in patients with brain metastases. J Neurooncol 1999, 44:275-281.

22. Suzuki $K$, Yamamoto $M$, Hasegawa $Y$, et al. Magnetic resonance imaging and computed tomography in the diagnoses of brain metastases of lung cancer. Lung Cancer 2004;46:357-360.

23. Ettinger DS, Wood DE, Aisner DL, et al. NCCN Clinical Practice Guidelines in Oncology: Non-Small Cell Lung Cancer. Version 2.2019. Obtained with permission from NCCN January 8,2019 . To view the most recent version, visit NCCN.org.

24. Levy A, Faivre-Finn C, Hasan B, et al. Diversity of brain metastases screening and management in non-small cell lung cancer in Europe: results of the European Organisation for Research and Treatment of Cancer Lung Cancer Group survey. Eur J Cancer 2018;93:37-46.

25. Yokoi K, Kamiya N, Matsuguma H, et al. Detection of brain metastasis in potentially operable non-small cell lung cancer: a comparison of CT and MRI. Chest 1999;115:714-719.

26. Silvestri GA, Gonzalez AV, Jantz MA, et al. Methods for staging non-small cell lung cancer: diagnosis and management of lung cancer, 3rd ed: American College of Chest Physicians Evidence-Based Clinical Practice Guidelines. Chest 2013;143(5 Suppl):e211S-250S.

27. Yuh WT, Fisher DJ, Runge VM, et al. Phase III multicenter trial of high-dose gadoteridol in MR evaluation of brain metastases. AJNR Am J Neuroradiol 1994;15:1037-1051.

28. Fink KR, Fink JR. Imaging of brain metastases. Surg Neurol Int 2013 4(Suppl 4):S209-219.

29. Bach PB, Cramer LD, Warren JL, et al. Racial differences in the treatment of early-stage lung cancer. N Engl J Med 1999;341:1198-1205.

30. Yu JB, Soulos PR, Cramer LD, et al. Comparative effectiveness of surgery and radiosurgery for stage I non-small cell lung cancer. Cancer 2015;121: 2341-2349.

31. Dalwadi SM, Szeja SS, Bernicker EH, et al. Practice patterns and outcomes in elderly stage I non-small-cell lung cancer: a 2004 to 2012 SEER analysis. Clin Lung Cancer 2018;19:e269-e276.

32. López-Encuentra A, Duque-Medina JL, Rami-Porta R, et al. Staging in lung cancer: is $3 \mathrm{~cm}$ a prognostic threshold in pathologic stage I non-small cell lung cancer? A multicenter study of 1,020 patients. Chest 2002;121: 1515-1520.

33. Gajra A, Newman N, Gamble GP, et al. Impact of tumor size on survival in stage IA non-small cell lung cancer: a case for subdividing stage IA disease. Lung Cancer 2003;42:51-57.

34. Palma DA, Tyldesley S, Sheehan F, et al. Stage I non-small cell lung cancer (NSCLC) in patients aged 75 years and older: does age determine survival after radical treatment? J Thorac Oncol 2010;5:818-824.

35. Cassidy RJ, Zhang X, Switchenko JM, et al. Health care disparities among octogenarians and nonagenarians with stage III lung cancer. Cancer 2018:124:775-784.

36. Peake MD, Thompson S, Lowe $D$, et al. Ageism in the management of lung cancer. Age Ageing 2003;32:171-177.

37. Japuntich SJ, Krieger NH, Salvas AL, et al. Racial disparities in lung cancer screening: an exploratory investigation. J Natl Med Assoc 2018 110:424-427.

38. Soneji S, Tanner NT, Silvestri GA, et al. Racial and ethnic disparities in early-stage lung cancer survival. Chest 2017;152:587-597. 